\title{
Judgments of eye level in light and in darkness
}

\author{
ARNOLD E. STOPER \\ California State University, Hayward, California \\ and \\ MALCOLM M. COHEN \\ NASA-Ames Research Center, Moffett Field, California
}

\begin{abstract}
Subjects judged eye level in the light and in the dark by raising and lowering themselves in a dental chair until a stationary target appeared to be at the level of their eyes. This method reduced the possibility of subjects' using visible landmarks as reference points for setting eye level during lighted trials, which may have contributed to artificially low estimates of the variability of this judgment in previous studies. Chair settings were $2.5^{\circ}$ higher in the dark than in the light, and variability was approximately $66 \%$ greater in the dark than in the light. These results are discussed in terms of possible interactions of two separate systems, one sensitive to the orientations of visible surfaces and the other sensitive to bodily and gravitational information.
\end{abstract}

Most people can readily determine whether a given target is above or below the level of their eyes. In the laboratory, they can easily position the target so that it appears to be at eye level (Cohen, 1973; Cohen \& Larson, 1974; Correia, Hixson, \& Niven, 1968; Ebenholtz, 1972; MacDougall, 1903; Matin et al., 1982; Nair, 1958; Schone, 1964; Sharp, 1934). They can do this for both a luminous target in the dark and an ordinary target in the light. In general, a target is considered to be at eye level when an imaginary line connecting the target to the eyes (the eyetarget line) is parallel to the gravitational horizontal.

To set a target to apparent eye level in the dark, an observer must use information from sources that specify: (1) the orientation of the head with respect to gravity, (2) the orientation of the line of sight with respect to the head, and (3) the orientation of the eye-target line with respect to the line of sight. ${ }^{1} \mathrm{We}$ will call the system that integrates information from these sources the "target/gravity" system.

In contrast, if an observer is standing on level ground in an illuminated environment, it is theoretically possible for him or her to position a target at eye level by means of purely optical information. Under these conditions, the positioning of a target to eye level requires only that the eye-target line be set parallel to the level ground plane, and this task does not require information about the direction of gravity, the position of the eyes in the head, or even the location of the image of the target on the retina. To set the eye-target line parallel to the ground plane, the observer need only judge, using the available depth cues, the distance between (1) the target and the ground and

This research was supported by funds under NASA Research Project No. 199-22-22-16, Grant NCC2-318. We thank Gail Adams and Kristen Lindseth for data collection, editorial comments, and support, and Tom Palmer and Geoff Apple for technical assistance.

A. E. Stoper's mailing address is: Department of Psychology, California State University, Hayward, CA 94542.
(2) his or her eyes and the ground, and simply change one or the other until these distances are equal. It is also theoretically possible to make a direct determination of the angle between the eye-target line and the ground plane solely on the basis of optical information from the surface of the ground without recourse to judgments of distance (Gibson, 1950, 1966; Gibson \& Cornsweet, 1952; Purdy, 1958; Sedgwick, 1980). We will call the system that uses optical information (e.g., depth cues) from visible surfaces to determine whether the eye-target line is parallel to the ground plane the "target/surface"' system.

In the dark, only the target/gravity system is available, but in the light both the target/gravity and the target/surface systems can operate. Because both systems can operate in the light, they may interact with one another to affect the process of setting a target to eye level. Perhaps the most basic experimental question we can ask in examining the nature of this interaction is concerned with the precision and accuracy of judgments: Are judgments of eye level more accurate and/or more precise in the light than in the dark? (We follow the convention of Howard, 1982 , in using the term "accuracy" to apply to constant errors, and the term "precision" to apply to variable errors.) Although several investigators have demonstrated decreased accuracy in the dark, we are aware of only one study that attempted to compare precision in the light with that in the dark; unfortunately, that study has a serious flaw. Thus, surprisingly, there has been no definitive answer in the literature to this question regarding precision; obtaining such an answer was a goal of the present study.

Judgments of eye level made in the light and in the dark were examined in detail by MacDougall (1903), who required his subjects to set an illuminated disk so that it appeared to be at the level of their eyes. MacDougall found that his subjects made a constant error in the light, setting the target approximately $0.13^{\circ}$ below true eye level; in the dark, the constant error was $0.61^{\circ}$ below true eye 
level. Thus, a target at true eye level would appear to be above true eye level, and it would also appear to be higher in the dark than in the light. This finding was confirmed by Sharp (1934), although his data indicated constant errors in the dark of about $3^{\circ}$, larger than the constant errors reported by MacDougall.

MacDougall found that variable errors are greater in the dark than in the light. He acknowledged that this could have been due, in part, to an uncontrolled flaw in his experimental design. If the subject repeatedly sets a target to subjective eye level in lighted surroundings, he or she can select a visual detail in the background and use it as an anchor; that is, he or she can set the target relative to the selected detail in each successive trial. Thus, the trials would not be truly independent, and an artificially low estimate of variability (i.e., an artificially high apparent precision) might result. A direct experimental comparison of the variability in judgments of eye level that are made in the dark versus those made in the light seems not to have been made since MacDougall's (1903) study.

\section{METHOD}

The present experiment was designed to prevent the subject from artificially increasing his or her precision by using background details as cues or anchors. One method to accomplish this would be to change the background itself between each trial; another would be to change the objective height of the subject between trials. We selected the latter method. A target was presented to the subject at one of two heights, and the subject adjusted the height of the motordriven dental chair in which he or she was seated until he or she perceived his or her eyes to be at the level of the target. During this process, the target remained fixed with respect to the background, so the relation of the target to any background details could not be used as a cue to the changing height of the subject. The use of the motor-driven chair, rather than the subject's own body movements, to effect an adjustment in the height of the subject's eyes minimized the possibility of his or her obtaining kinesthetic cues.

\section{Experimental Chamber}

The experiment was performed in a light-tight chamber that measured $3.1 \times 3.1 \mathrm{~m}$, with a height of $2.6 \mathrm{~m}$. Homogeneous medium gray photographic backdrop paper was suspended from the ceiling in front of all visible walls to mask any obvious surface markings. The paper was hung approximately $0.8 \mathrm{~m}$ to the subject's left, $1.2 \mathrm{~m}$ to his or her right, and $2.0 \mathrm{~m}$ ahead of his or her eyes. The floor was gray concrete with little obvious surface texture.

\section{Illumination}

For the lighted viewing conditions, illumination was provided by baffled fluorescent lamps recessed into the ceiling of the chamber; the light intensity at the front wall was $9 \mathrm{~cd} / \mathrm{m}^{2}$. For the dark viewing conditions, no extraneous sources of illumination were visible to the subject.

\section{Apparatus}

Target. The target, a pinpoint image $(<2 \mathrm{~mm}$ in diameter) provided by a $0.5-\mathrm{mW}$ 632-nm laser (Spectra Physics Model Number 155), was projected in the subject's midsagittal plane onto the backdrop paper covering the wall at a distance of $2.0 \mathrm{~m}$ from his or her eyes. The laser beam was attenuated to $10 \%$ of its original intensity by a neutral density filter, which thereby reduced the possibility of having scattered light illuminate any surfaces in the room.
Chair. Throughout the study, the subject was seated in a dental chair. The chair was raised hydraulically by an electric motor and lowered by bleeding air pressure from the hydraulic system. The range of motion for the chair was $46 \mathrm{~cm}$ from top to bottom; the upward velocity was about $4 \mathrm{~cm} / \mathrm{sec}$, and the downward velocity was variable, with a maximum of $7 \mathrm{~cm} / \mathrm{sec}$. Any acceleration or deceleration that might have affected the otoliths would be confined to the very brief time at the stoppage of the chair's motion and would not influence the judgments of eye level.

A toggle switch and a joystick were mounted on the right armrest of the chair to allow the subject to control his or her own motion. Pushing the toggle switch forward raised the chair; pulling backward on the joystick lowered the chair. The height of the chair could also be adjusted by the experimenter, who had independent foot pedal controls.

The dental chair was provided with an adjustable headrest, against which the subject was instructed to keep his or her head. Although no additional restraints were used, the headrest effectively restricted pitch movements of the head. Head pitch was monitored with the aid of goggles, LEDs, and a video system. Motions of the subject's head about the roll axis were neither restrained nor monitored; it was assumed that these motions would not systematically influence judgments of eye level. There was no need to fix the vertical position of the subject's head with respect to the chair, since the important variable was the height of the eyes relative to the target, and this was measured by the video system.

Goggles. All viewing was binocular. The subject wore transparent protective goggles with an oval faceplate that measured $10 \times 6 \mathrm{~cm}$. Two LEDs were mounted approximately $1 \mathrm{~cm}$ apart on the outside of the goggles along a horizontal line from front to back. The LEDs, which were not visible to the subject, were used by the experimenter both to monitor the height of the eyes and to ensure the continuous upright orientation of the subject's head.

Video system. A video image of the goggle-mounted LEDS was used to determine the height of the subject's eyes and the orientation of the subject's head, both in the dark and in the light. A separate video system was used to record the height of the laser target viewed by the subject.

\section{Procedure}

Subjects. Ten subjects participated in this study, 6 males and 4 females. Eight subjects were paid for their participation; the remaining 2 subjects, unpaid, were the authors of this paper.

Instructions. The subject was instructed to adjust the height of his or her chair on each trial until his or her eyes were at the same level as the target. The subject was further instructed to keep his or her head steady against the headrest and to keep his or her eyes closed at all times except when he or she was actively adjusting the height of the chair.

Data collection and analyses. After each setting was made, the experimenter reminded the subject to close his or her eyes. The experimenter then moved the chair to a new starting position, either near the top or near the bottom of its range, and repositioned the target to one of two fixed positions, separated by a difference in height of $2.6 \mathrm{~cm}$. In the rare event that the experimenter detected a change in the subject's head position, she stopped the experiment momentarily and instructed the subject to reposition his or her head.

Each block of trials was run either in the light or in the dark, and 10 measures were obtained under each condition. Thus, the experiment consisted of three factors of two levels each that were repeated 10 times, yielding a total of 80 trials per subject. The factors were as follows: (1) lighting condition (light vs. dark), (2) direction of movement needed to align with target (up vs. down), and (3) target position (target high vs. target low).

Data, consisting of the actual position of the subject's eyes (as indicated by the goggle-mounted LEDs) when the subject judged his or her eyes to be at the level of the target and the variability 
Table 1

Mean Settings to Eye Level: Degrees of Deviation from Ohjective Values (Constant Errors)

\begin{tabular}{lrrrrrrrr}
\hline $\begin{array}{l}\text { Lighting: } \\
\text { Movement: } \\
\text { Position: }\end{array}$ & $\begin{array}{c}\text { Light } \\
\text { Up } \\
\text { High }\end{array}$ & $\begin{array}{c}\text { Light } \\
\text { Up } \\
\text { Low }\end{array}$ & $\begin{array}{c}\text { Light } \\
\text { Down } \\
\text { High }\end{array}$ & $\begin{array}{c}\text { Light } \\
\text { Down } \\
\text { Low }\end{array}$ & $\begin{array}{c}\text { Dark } \\
\text { Up } \\
\text { High }\end{array}$ & $\begin{array}{c}\text { Dark } \\
\text { Up } \\
\text { Low }\end{array}$ & $\begin{array}{r}\text { Dark } \\
\text { Down } \\
\text { High }\end{array}$ & $\begin{array}{c}\text { Dark } \\
\text { Down } \\
\text { Low }\end{array}$ \\
\hline P.A. & -1.35 & -1.18 & -0.30 & -0.91 & -0.98 & -0.49 & 2.59 & 2.92 \\
M.I. & 1.31 & -0.23 & 3.07 & 1.29 & 6.38 & 4.46 & 9.57 & 8.04 \\
J.I. & 2.01 & 1.67 & 3.00 & 2.78 & 6.00 & 6.74 & 6.89 & 7.18 \\
M.A. & -1.93 & -2.06 & -0.80 & -0.93 & -1.37 & -0.92 & -1.26 & -1.33 \\
A.R. & 1.40 & 1.44 & 1.82 & 2.23 & 2.57 & 3.01 & 2.98 & 2.85 \\
B.U. & -1.39 & -0.47 & -0.40 & -0.10 & -1.86 & -0.18 & -0.41 & -0.32 \\
M.E. & 0.58 & -0.24 & 2.06 & 0.92 & 1.31 & 1.73 & 6.40 & 3.89 \\
G.U. & -0.55 & -0.37 & -0.40 & -0.78 & -0.81 & 0.06 & -1.38 & -0.41 \\
L.I. & -1.62 & -1.53 & -0.20 & 0.33 & 2.36 & 2.92 & 5.03 & 6.83 \\
D.A. & 1.43 & -0.90 & 2.63 & 0.27 & 5.48 & 3.42 & 7.11 & 4.53 \\
Sum & -0.11 & -3.87 & 10.48 & 5.10 & 19.08 & 20.75 & 37.52 & 34.18 \\
Mean & -0.01 & -0.39 & 1.05 & 0.51 & 1.91 & 2.08 & 3.75 & 3.42 \\
SD & 1.43 & 1.12 & 1.52 & 1.23 & 3.02 & 2.36 & 3.67 & 3.17 \\
\hline
\end{tabular}

of these measures (as represented by average unsigned deviations from the mean values and by standard deviations), were collected and analyzed in separate three-way ANOVA matrices.

\section{RESULTS}

Constant errors, as represented by mean settings, variable errors, as represented by both average unsigned deviations from the mean, and standard deviations were calculated for each of the eight different experimental conditions for each subject. These data are presented in Tables 1,2 , and 3 , respectively.

The constant errors, which indicate accuracy, and the variable errors (both average unsigned deviations and standard deviations), which indicate precision, were evaluated by ANOVAs.

\section{Constant Errors}

The ANOVA on the constant errors (mean settings) showed a significant effect of lighting condition $[F(1,9)=$
$12.60, p<.01]$, movement $[F(1,9)=15.55, p<.01]$, and the interaction of lighting condition with target position $[F(1,9)=7.73, p<.05]$.

Lighting condition. The mean setting of the subjects' eyes in the dark was $2.79^{\circ}$ above the objective position of the target, but in the light, it was only $.29^{\circ}$ above the objective position. This finding is in general agreement with that of MacDougall, although our constant errors in the light are approximately twice as large as those that he reported; in the dark, our constant errors are about five times as large as those he reported. However, our findings in the dark are in close agreement with those of Sharp (1934). The increased magnitude of the constant errors reported here and by Sharp can probably be attributed to differences in psychophysical methods and to the more complete elimination of visual cues in the more recent studies.

Movement. When the initial position of the chair was near the bottom of its range, thereby necessitating an upward movement, the mean setting of eye level was $.90^{\circ}$

Table 2

Unsigned Average Deviations of Settings to Eye Level: Degrees of Average Deviations from Individual Mean Settings (Variable Errors)

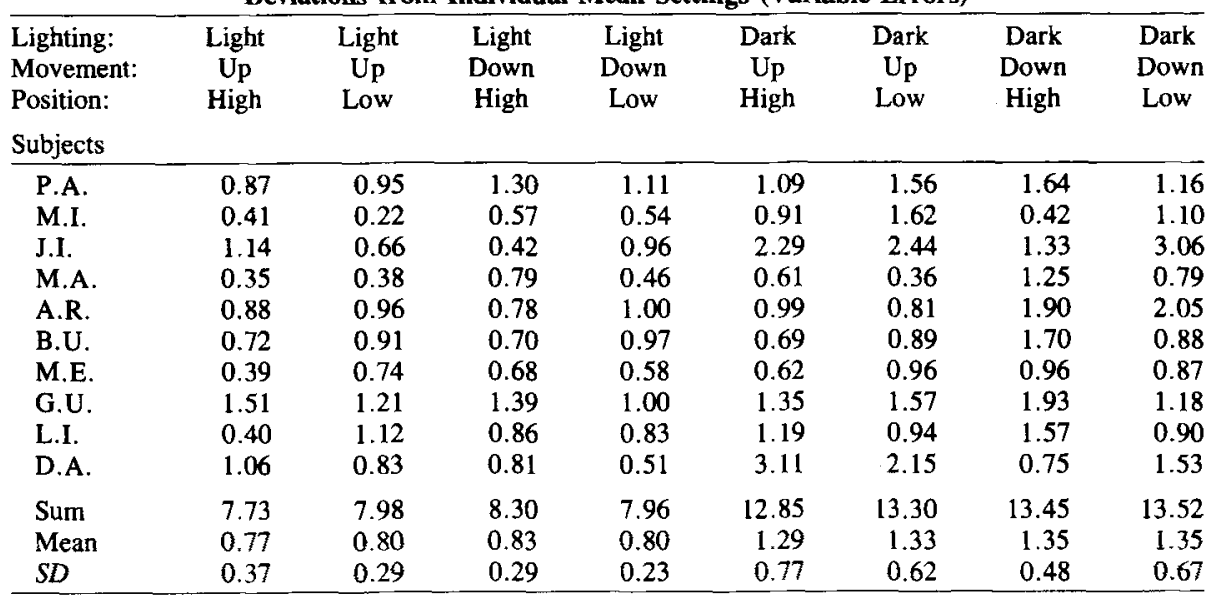


Table 3

Standard Deviations of Settings to Eye Level: Computed in Degrees and Based on Each Group of 10 Settings (Variable Errors)

\begin{tabular}{lrrrrrrrr}
\hline $\begin{array}{l}\text { Lighting: } \\
\text { Movement: } \\
\text { Position: }\end{array}$ & $\begin{array}{c}\text { Light } \\
\text { Up } \\
\text { High }\end{array}$ & $\begin{array}{c}\text { Light } \\
\text { Up } \\
\text { Low }\end{array}$ & $\begin{array}{c}\text { Light } \\
\text { Down } \\
\text { High }\end{array}$ & $\begin{array}{c}\text { Light } \\
\text { Down } \\
\text { Low }\end{array}$ & $\begin{array}{c}\text { Dark } \\
\text { Up } \\
\text { High }\end{array}$ & $\begin{array}{c}\text { Dark } \\
\text { Up } \\
\text { Low }\end{array}$ & $\begin{array}{c}\text { Dark } \\
\text { Down } \\
\text { High }\end{array}$ & $\begin{array}{c}\text { Dark } \\
\text { Down } \\
\text { Low }\end{array}$ \\
\hline P.A. & 1.01 & 1.07 & 1.47 & 1.26 & 1.57 & 1.84 & 2.17 & 1.44 \\
M.I. & 0.49 & 0.28 & 0.72 & 0.76 & 1.09 & 2.37 & 0.59 & 1.44 \\
J.I. & 1.42 & 0.76 & 0.52 & 1.18 & 2.76 & 2.86 & 1.49 & 3.80 \\
M.A. & 0.44 & 0.45 & 0.88 & 0.59 & 0.80 & 0.50 & 1.54 & 1.20 \\
A.R. & 1.16 & 1.16 & 0.93 & 1.27 & 1.33 & 1.03 & 2.37 & 2.49 \\
B.U. & 0.94 & 1.03 & 0.91 & 1.22 & 0.95 & 1.05 & 2.02 & 1.01 \\
M.E. & 0.56 & 0.92 & 0.83 & 0.83 & 0.83 & 1.25 & 1.47 & 1.47 \\
G.U. & 2.46 & 1.84 & 2.44 & 1.63 & 2.35 & 2.23 & 2.61 & 1.93 \\
L.I. & 0.49 & 1.29 & 1.07 & 1.07 & 1.51 & 1.18 & 2.10 & 1.23 \\
D.A. & 1.27 & 1.04 & 1.03 & 0.61 & 3.43 & 2.61 & 1.00 & 1.85 \\
Sum & 10.24 & 9.84 & 10.80 & 10.42 & 16.62 & 16.92 & 17.36 & 17.86 \\
Mean & 1.02 & 0.98 & 1.08 & 1.04 & 1.66 & 1.69 & 1.74 & 1.79 \\
SD & 0.59 & 0.41 & 0.51 & 0.32 & 0.85 & 0.76 & 0.60 & 0.79 \\
\hline
\end{tabular}

above the target; when the initial movment was downward, the mean setting was $2.18^{\circ}$ above the target. In classical psychophysical terms, the effects of the direction of movement can be regarded as "errors of anticipation," in that, for each direction of movement, the subjects tended to stop their adjustments before they reached their mean settings. A similar effect, which probably represents a tendency to accept the initial stimulus conditions as a standard, was noted by Sharp (1934).

Lighting condition $\times$ target position. Although target position was not statistically significant as a main effect, its interaction with lighting condition was significant. In the light, with the target in the "high" position, subjects set their eyes $.52^{\circ}$ above the target; with the target in the "low" position, they set their eyes only $.06^{\circ}$ above the target. In the dark, the subjects placed their eyes $2.83^{\circ}$ above the target when the target was high and $2.75^{\circ}$ above the target when it was low. When the target was low and the room was illuminated, the floor surface could influence judgments of eye level; when the target was high and the room was illuminated, the influence of the floor surface, more removed from the target, might have been reduced. When the room was in total darkness, the floor or other environmental surfaces could have no effect and the position of the target relative to the floor could not influence the apparent eye level. This finding suggests that the more detailed the visual array and the closer it is to the target, the greater may be its influence on judgments of eye level.

\section{Variable Errors}

The ANOVA on the variable errors (average unsigned deviations from the mean) revealed a significant $[F(1,9)$ $=20.39, p<.01$ ] effect of lighting. In the light the mean variable error was only $.80^{\circ}$, but in the dark it was $1.33^{\circ}$. [The ANOVA on the standard deviations revealed similar effects, with mean values of $1.03^{\circ}$ in the light and $1.72^{\circ}$ in the dark; $\left.F(1,9)=11.40, \mathrm{p}<.01.\right]$ The values of average unsigned deviations from the mean can be com- pared with those reported by MacDougall, who found a similar pattern of increased variability in the dark; his variable errors (average unsigned deviations, which he called "mean variations") were approximately $.13^{\circ}$ in the light and $.52^{\circ}$ in the dark, considerably smaller than those reported here. Again, the larger variability that we obtained may be attributed to differences in the methods of adjustment and to our more complete control of the extraneous cues.

\section{DISCUSSION}

Our original experimental question was: "Are judgments of eye level more accurate and/or more precise in the light than in the dark?' 'For the conditions of this study, the answer for both accuracy and precision is "yes." In the light, the mean constant error was $.29^{\circ}$; in the dark, the mean constant error was $2.79^{\circ}$. Since head position was controlled, this implies that, if the subject were fixating a target at apparent eye level, his or her eyes would be rotated $.29^{\circ}$ downward in the light and $2.79^{\circ}$ downward in the dark. The variable errors were also significantly smaller in the light than in the dark; the average unsigned deviations from the mean were $.80^{\circ}$ in the light and $1.33^{\circ}$ in the dark; the standard deviations were $1.03^{\circ}$ in the light and $1.72^{\circ}$ in the dark. It is clear that optical information is somehow used to improve both the precision and accuracy of eye-level judgments.

Several previous investigators (Hoppeler, 1913; MacDougall, 1903; Sandström, 1951; Sharp, 1934) have reported greater accuracy in judgments of eye level in the light than in the dark; they have also reported that eye level is judged to be too low in the dark (i.e., visible targets in the dark appear to be above their true physical locations).

Other investigators have induced errors in judgment of visual direction by various manipulations of the visuomotor system, and have found that these errors were much greater in the dark than in the light (Aubert, 1861, cited 
in Howard, 1982; Matin et al., 1982; Mittelstaedt, 1984; Shebilske, 1981; Stark \& Bridgeman, 1983). One plausible explanation for the greater accuracy in the light in all these experiments is that when the target/surface system and the target/gravity system are both available, as they are in the light, the target/surface system dominates the judgment and the target/gravity system is effectively suppressed. If the target/surface system is more accurate than the target/gravity system, judgments made in lighted surroundings will be more accurate; if the target/surface system is also more precise, these judgments will be more precise as well. We will call this explanation the "dominance" hypothesis.

The dominance hypothesis is supported by a large body of evidence showing that when there is a conflict between visual and sensorimotor information, vision will dominate (see Pick, Warren, \& Hay, 1969). However, one problem with the application of this hypothesis in our particular situation is that there is no direct evidence that the target/surface system acting alone is either more accurate or more precise than the target/gravity system acting alone in the determination of eye level. In fact, the accuracy or precision of the target/surface system acting in isolation seems never to have been measured. Furthermore, studies investigating conflict between visual and gravitational information in perception of the vertical or horizontal have indicated that the system supplying gravitational information is not suppressed, but rather that there is a compromise between the visual and the gravitational systems (Kleinhans, 1970; Mittelstaedt, 1984; Perrone, 1977; Witkin, 1949). Another hypothesis for the improved precision (but not accuracy) of judgments made in the light is suggested by studies showing that body sway is less in the light than in the dark (Bles, Kapteyn, \& De Wit, 1977; Edwards, 1946; Lee \& Lishman, 1975; Witkin \& Wapner, 1950). The accepted explanation for this observation is that the visual system is more sensitive to lowfrequency changes than is the vestibular/proprioceptive system, and can thus aid in providing feedback from slow swaying movements. In our study, it is possible that some of the variability in the dark was due to a low-frequency drift in the target/gravity system, and that the improvement in the light was due to the elimination of that lowfrequency drift by means of visual information. (This might be the case even for a seated subject with no actual body sway.) We call this explanation the "stabilization" hypothesis. It allows for the possibility that the target/gravity system is not suppressed in the light but is assisted by the use of stabilizing optical information.

One simple mechanism by which this "stabilization" could occur is through the use of visible surfaces in the environment as a frame of reference, such as may have occurred in the MacDougall study. Visible landmarks may have been used to allow for repetition of some particular judgment of eye level. Another possibility is the use of head-referenced landmarks such as the borders of the visual field and the nose. Such landmarks, in particular the nose, have been suggested as the main source of information for visual direction relative to the observer
(Bower, 1974). Although our experimental design minimized the use of environment-referenced landmarks by changing the elevation of the subject between trials, it did allow the use of head-referenced landmarks. In fact, the goggles that we used may have provided additional head-referenced landmarks. These landmarks moved with the subject as he or she changed his or her elevation, and could have provided information about a change in line of sight relative to the head. Since the subject kept his or her head immobile throughout the experiment, these landmarks could also have directly provided information about the position of the line of sight relative to gravity. Thus, once the subject had decided on a particular eye level by means of either the target/surface or target/gravity systems, he or she could improve the precision of successive judgments by setting the chair so that some headreferenced landmark was the same distance from the target light in successive trials.

The usefulness of the nose as a landmark in improving the precision of judgments of visual direction has been put to a direct test by Shebilske and Nice (1976). These investigators found that errors in visual direction were not reduced by the visibility of the subject's nose. They did not, however, investigate the effects of other headreferenced landmarks, in particular the borders of the visual field, which would be present in the light. It remains possible that these other head-referenced landmarks do provide useful information concerning visual direction, and that this information was responsible for the improved precision in the light found in the present experiment.

Our data do not permit a decision between the dominance and the stabilization hypotheses. Needed for this decision are data regarding (1) the accuracy and precision of the target/surface system acting alone, (2) the extent to which the availability of head-referenced landmarks reduce postural sway and/or improve precision of eye-level judgments, and (3) the correlation between reduction of postural sway, achieved by whatever means, and an increase in precision of eye-level judgments.

\section{REFERENCES}

Bles, W., KaPTeyn, T. S., \& DE WIT, G. (1977). Effects of visualvestibular interaction on human posture. Advances in Oto-RhinoLaryngology, 22, 111-118.

BOWER, T. G. R. (1974). Development in infancy. San Francisco: W. H. Freeman.

CoHEN, M. M. (1973). Elevator illusion: Influences of otolith organ activity and neck proprioception. Perception \& Psychophysics, 14, 401-406.

COHEN, M. M., \& LARSON, C. A. (1974). Human spatial orientation in the pitch dimension. Perception \& Psychophysics, 16, 508-512.

Correia, M. J., Hixson, W. C., \& Niven, J. I. (1968). On predictive equations for subjective judgments of vertical and horizon in a force field. Acta Oto-Laryngologica, Suppl. 230.

EBENHOLTZ, S. M. (1972). The constancy of object orientation: Effects of target inclination. Psychologische Forschung, 35, 178-186.

EDWARDS, A. S. (1946). Body sway and vision. Journal of Experimental Psychology, 36, 526-535.

GIBSON, J. J. (1950). The perception of the visual world. Boston: Houghton Mifflin.

GiBson, J. J. (1966). The senses considered as perceptual systems. Boston: Houghton Mifflin. 
Gibson, J. J., \& Cornsweet, T. (1952). The perceived slant of visual surfaces-optical and geographical. Joumal of Experimental Psychology, 44, 11-15.

HOPPELER, P. (1913). Über den Stellungsfaktor der Sehrichtungen; eine experimentelle Studie. Zeitschrift für Psychologische und Physiologische Sinnesorgane, 66, 249-262.

Howard, I. P. (1982). Human visual orientation. New York: Wiley.

Kleinhans, J. L. (1970). Perception of spatial orientation in sloped, slanted and tilted visual fields. Unpublished doctoral dissertation, Rutgers University.

LEE, D. N., \& LishmaN, J. R. (1975). Visual proprioceptive control of stance. Journal of Movement Studies, 1, 87-95.

MacDougall, R. (1903). The subjective horizon. Psychological Review Monograph, Suppl. 4, 145-166.

Matin, L., Picoult, E., Stevens, J. K., Edwards, M. W., JR., Young, D., \& MACARThUR, R. (1982). Oculoparalytic illusion: Visual-field dependent spatial localizations by humans partially paralyzed with curare. Science, 216, 198-201.

MITTELSTAEDT, H. (1984, September). The effect of visual on extraretinal information about the vertical: Suppression or superposition? Paper presented at the XXIII International Congress of Psychology, Acapulco.

NAIR, P. J. (1958). Relationships between postural and conative aspects of organismic state and perceptual localization of the apparent horizon. Unpublished master's thesis, Clark University.

Perrone, J. A. (1977). The visual horizon and eye level judgements. A psychophysical approach to spatial orientation perception. Unpublished master's thesis, University of Canterbury.

Pick, H., Warren, D., \& HaY, J. (1969). Sensory conflicts in judgments of spatial direction. Perception \& Psychophysics, 6, 203-205.

PURDY, W. C. (1958). The hypothesis of psychophysical correspondence in space perception. Doctoral dissertation, Cornell University. (Ann Arbor: University Microfilms, No. 58-5594)

SANDSTRÖM, C. I. (1951). Orientation in the present space. Uppsala: Almqist \& Wicksell.
SCHONE, H. (1964). On the role of gravity in human spatial orientation. Aerospace Medicine, 35, 764-772.

SEDGWICK, H. A. (1980). The geometry of spatial layout in pictorial representation. In M. Hagen (Ed.), The perception of pictures (pp. 3388). New York: Academic Press.

SHARP, W. L. (1934). An experimental study concerning visual localization in the horizontal plane. Jourmal of Experimental Psychology, 17, 787-797.

SHEBILSKE, W. L. (1981). Visual direction illusions in everyday situations: Implications for sensorimotor and ecological theories. In D. F. Fisher, R. A. Monty, \& J. W. Senders (Eds.), Eye movements: Cognition and visual perception (pp. 95-110). Hillsdale, NJ: Erlbaum.

SHEbiLSKe, W. L., \& NiCE, D. S. (1976). Optical insignificance of the nose and the Pinocchio effect in free-scan visual straight-ahead judgments. Perception \& Psychophysics, 20, 17-20.

STARK, L., \& BRIDGEMAN, B. (1983). Role of corollary discharge in space constancy. Perception \& Psychophysics, 34, 371-380.

WitKIn, H. A. (1949). Perception of body position and of the position of the visual field. Psychological Monographs: General and Applied, 63(7), 1-46.

WITKIN, H. A., \& WAPNER, S. (1950). Visual factors in the maintenance of upright posture. American Journal of Psychology, 63, 31-50.

\section{NOTE}

1. If the target image is on the fovea, the eye-target line coincides with the line of sight; if not, the degree of deviation of the target image from the fovea corresponds to the degree of deviation of the eye-target line from the line of sight.

(Manuscript received September 16, 1985; revision accepted for publication July 30,1986 .) 